\title{
Impact of COVID-19 pandemic on athletes with disabilities preparing for the Paralympic Games in Tokyo
}

\author{
Piotr Urbański ${ }^{1^{*} \mathbb{D}}$, Łukasz Szeliga ${ }^{2}$ and Tomasz Tasiemski ${ }^{1}$
}

\begin{abstract}
Objective: The main aim of the study was to assess the impact of COVID-19 pandemic on athletes preparing for the Tokyo 2021 Paralympic Games during 1 month of lockdown in Poland. The study involved 166 athletes (106 male, 66 female), members of either the Polish Paralympic Committee or the Polish Sports Association for the Disabled'Start', two organizations responsible for managing and regulating sports played by persons with disabilities in Poland.

Results: Athletes with disabilities have been strongly affected by the pandemic and the resultant lockdown. The majority of respondents reported that they trained at home (88.6\%), whereas $60.2 \%$ of athletes trained outdoors, and $12 \%$ suspended their training regimens altogether. Only $5.4 \%$ of athletes had some access to sport facilities. The athletes reduced their weekly training time by almost half ( $9.4 \mathrm{~h} /$ week vs. $5.3 \mathrm{~h} /$ week), a statistically significant difference $(\mathrm{t}=16.261, \mathrm{p}<0.001)$.
\end{abstract}

Keywords: Athletic performance, COVID-19, Lockdown, Paralympic Games, Physical disability, Paralympic athletes

\section{Introduction}

From the end of 2019 onwards, the COVID-19 pandemic caused by the SARS CoV-2 (Severe Acute Respiratory Syndrome Coronavirus) has affected all spheres of human activity, including mostly healthcare system but also economy, tourism, education and sport. Geographically, the pandemic has impacted all regions of the world. By mid-March 2020, Europe had become the epicenter of the epidemic, reporting over $40 \%$ of globally confirmed cases; as of 28 April 2020, 63\% of global demises attributable to the virus were reported from this WHO Region [1]. In Poland, the government data for the period between March 20 and April 30, 2020 record 14,826 diagnosed COVID-19 cases and 714 resultant deaths (Fig. 1). Many European countries introduced diverse

\footnotetext{
*Correspondence: urbanski@awf.poznan.pl

${ }^{1}$ Department of Adapted Physical Activity, Poznan University of Physical

Education, Poznań, Poland

Full list of author information is available at the end of the article
}

countermeasures against the spread of infection, including the so-called lockdowns of variable severity. In early April 2020, the extent of lockdown measures varied from country to country, with some banning any kind of interhousehold mingling and outdoor activities, some allowing certain types of activities (e.g. Poland, Germany and the UK) and some merely recommending precautionary social distancing measures (Sweden) [2].

The introduction of countermeasures against the spread of COVID-19 and fear linked with the pandemic resulted in cancellation or suspension of almost all sport activities and events around the world, including the 2020 Olympic and Paralympic Games in Tokyo. In effect, the pandemic negatively impacted sport from grassroots physical activity to elite sport events [3]. The limits imposed on physical activity are predicted to negatively impact the health and future performance of athletes living under lockdowns [4]. The enforced isolation is expected to lead to cessation of organized training/competitive activities and prolonged periods of

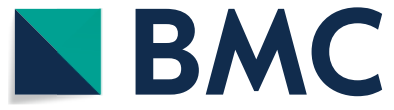

(c) The Author(s) 2021. This article is licensed under a Creative Commons Attribution 4.0 International License, which permits use, sharing, adaptation, distribution and reproduction in any medium or format, as long as you give appropriate credit to the original author(s) and the source, provide a link to the Creative Commons licence, and indicate if changes were made. The images or other third party material in this article are included in the article's Creative Commons licence, unless indicated otherwise in a credit line to the material. If material is not included in the article's Creative Commons licence and your intended use is not permitted by statutory regulation or exceeds the permitted use, you will need to obtain permission directly from the copyright holder. To view a copy of this licence, visit http://creativecommons.org/licenses/by/4.0/. The Creative Commons Public Domain Dedication waiver (http://creativecommons.org/publicdomain/zero/1.0/) applies to the data made available in this article, unless otherwise stated in a credit line to the data. 


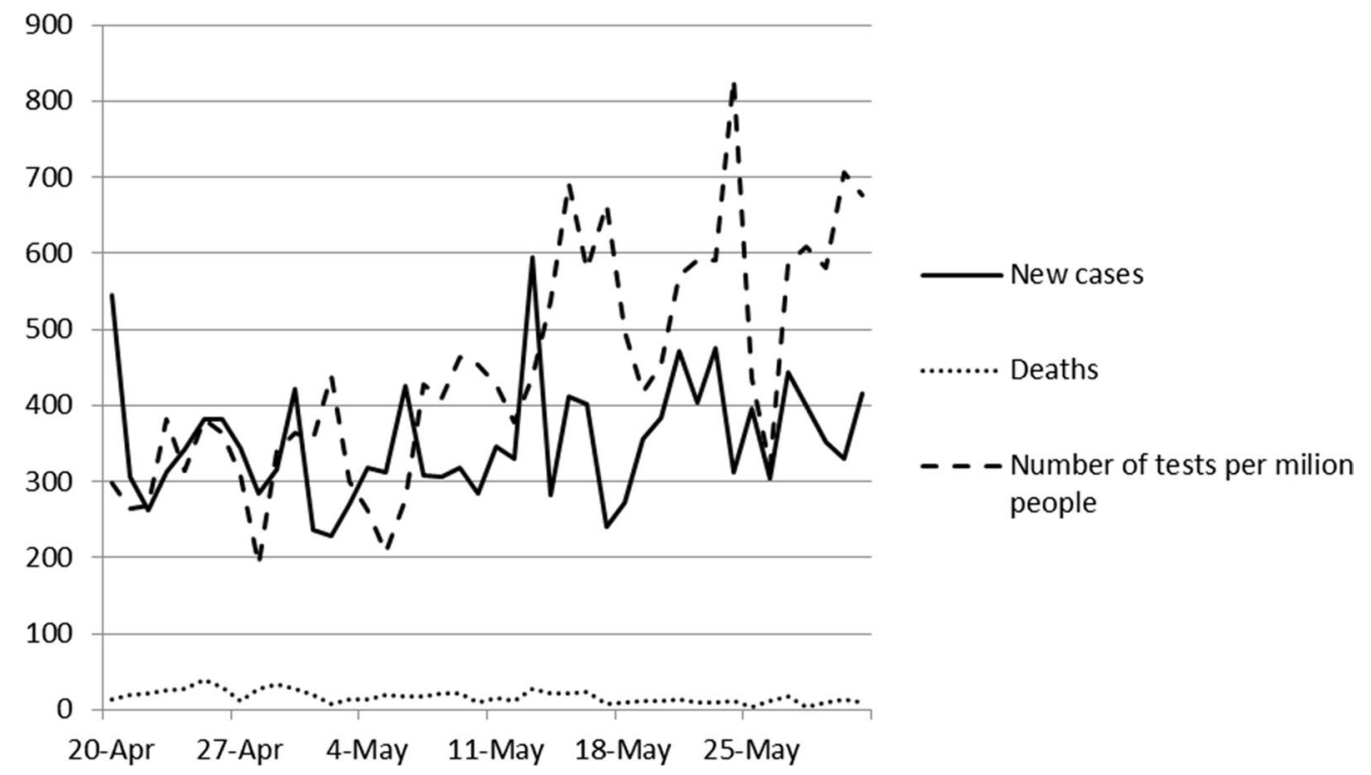

Fig. 1 Development of COVID-19 in Poland between April 20 and May 30, 2020

inactivity, broken up by rare training sessions in suboptimal conditions (no or limited access to training facilities and equipment) [2, 3, 5]. Team relationships will likely deteriorate due to limited socializing opportunities between athletes, coaches and team support networks. Finally, the limits imposed on travel will further impact athletes with disabilities who were already suffering from mobility issues attributable to inadequate public transport infrastructure designed to accommodate people with disabilities $[6,7]$.

Scholarly reports published so far on the pandemic's impact have assessed the influence of COVID-19 on the performance of athletes, underlining the need for regular physical activity during the period of social isolation $[5,8,9]$. Some of the studies report that the influence of pandemic is differentiated, $40.5 \%$ of inactive individuals became even less active, and only $22.4 \%$ of active individuals became less active. Comparatively, $33 \%$ of inactive individuals became more active while $40.3 \%$ of active individuals became even more active [10]. Other studies indicate that the decreased level of physical activity of children and adults living under lockdowns may expose them to an increased risk of obesity, associated with various immediate and long-term comorbidities, such as sleep apnea, hypertension, type 2 diabetes, heart disease, stroke and reduced immunity $[5,11]$. The psychophysiological conditions of life under lockdown and in quarantine may negatively affect the activity of the sympathetic nervous system: the uncertainty and isolation may result in abnormally prolonged release of cortisol and catecholamine, potentially leading to different pathologies and psychopathologies, such as anxiety, depression, loneliness or sleep disorders $[6,12]$.

Considering social repercussions of the COVID-19 pandemic, persons with disabilities constitute a distinct group in regard to their health conditions [13] and health risks [14]. The studies demonstrate that people with specific comorbidities associated with disabilities (e.g. impaired immune function, either by disease or medication, renal/hepatic dysfunction, cardiovascular diseases, lung conditions) may exhibit more serious symptoms when suffering from the COVID-19 $[15,16]$ and therefore require additional safety measures, such as stringent social isolation. Nevertheless, it is well known that physical activity, sport and socializing play a key role in physical rehabilitation of people with disabilities [17]. Participation in physical activity and sport measurably increases their self-sufficiency and psychophysical resilience. Benefits of physical activity are often not deemed significant enough to justify relaxing social distancing rules in the context of the perceivably greater threat of COVID-19. The above holds especially true for athletes with disabilities who train for competitions under the lockdown.

Although one study [18] demonstrated that time spent engaging in sedentary screen time activities increased during the COVID-19 pandemic, it also highlighted the general resilience of athletes, with no discernible differences in training, fitness, or dietary intake over a short (3 months) period. Nevertheless, this research covers only one specific discipline and the topic demands further investigation. During March and June 2020 in 
Poland, all sports facilities and gyms were closed due to governmental mitigation measures (social isolation and social distancing). In result, athletes could only train outdoors, most often individually, often without any direct input from their coach. Since persons with disabilities often need support of their caregivers, athletes with disabilities face unique difficulties when forced to train individually.

In light of the situation described above, the main aim of the study was to assess the situation of athletes with disabilities preparing for the Tokyo 2021 Paralympic Games during the lockdown period (from March 20 to April 30, 2020) in Poland. We were particularly interested in necessary modifications in training caused by the governmental countermeasures against the COVID-19 pandemic.

\section{Main text \\ Methods \\ Survey design}

The questionnaire was prepared in cooperation with the European Paralympic Committee and Polish Paralympic Committee, including the input of sports section coaches, a sports psychologist and a physiotherapist (Additional file 1). The questionnaire has been designed so that the respondents can complete it quickly and without undue effort. The survey included questions about the effect of the COVID-19 on the average training time during the pandemic (in relation to the original training schedule), satisfaction with training, accessibility of sport facilities and other aspects of sports performance.

\section{Procedures}

Study participants were registered members of the Polish Paralympic Committee or the Polish Sports Association for the Disabled'Start', two organizations responsible for managing and regulating sports played by persons with disabilities in Poland. All participants were training in preparation for the Paralympic Games in Tokyo. Participants were recruited in May 2020 and invited to complete a cross-sectional survey. During the first week of June, 200 athletes were electronically sent a link to an online survey hosted by Google Forms, with completion reminders sent weekly during the next two weeks. A total of 188 surveys were completed (response rate $94 \%$ ), with 22 surveys excluded due to missing data: in result, the study considered data gathered from 166 surveys.

\section{Participants}

Male respondents constituted the majority of the study participants (63.9\%). The main type of disability reported by participating Paralympic athletes was spinal cord injury i.e., paraplegia and tetraplegia (25.9\%), followed by limb amputations (22.2\%). The mean age of study participants was 33 years $(\mathrm{SD}=11.7)$, and the mean time since injury or diagnose of disease was 20 years $(\mathrm{SD}=12.5)$. Study participants represented 15 Paralympic sport disciplines. The most commonly represented sport was athletics $(23.5 \%)$, whereas the average training experience in years amounted to $10(\mathrm{SD}=7.0)$. The respondents' characteristics are presented in Table 1.

\section{Statistical analysis}

Descriptive data was presented as $n$, percent, mean and standard deviation $(S D)$. To assess the difference between planned and executed training time, the independent samples $t$ Test was performed. All statistical analyses were performed with the IBM Statistical Package for Social Sciences software (IBM SPSS Statistics version 21, Chicago, IL, USA). The level of significance was set at $p \leq 0.05$.

\section{Results and discussion}

The COVID-19 pandemic has affected athletes with disabilities and sports institutions all over the word. A new challenge in the contemporary world of sport, the pandemic demanded and continues to demand extraordinary flexibility and resilience from sport managers, who have to adapt to rapidly shifting conditions. This study's aim was to assess the situation and training opportunities for elite athletes with disabilities preparing to participate in the Tokyo Paralympic Games 2021 and to indicate relevant factors that could hamper their performance during this elite sport event.

The results of this study showed that the vast majority of athletes were affected by the pandemic and/or governmental countermeasures such as lockdowns. Even though during the study period only $9 \%$ of athletes were quarantined and $1.8 \%$ of athletes and $0.6 \%$ of coaches contracted COVID-19, the social distancing measures almost universally affected athletes' training regimens (e.g. closed venues/gyms or limitations for total number of people at sport venues). The majority of respondents reported that they trained at home $(88.6 \%), 60.2 \%$ of athletes trained outdoors, and $12 \%$ suspended their training regimens altogether. Only $5.4 \%$ of athletes had some form of access to sport facilities. On average, the athletes reduced their weekly training time by almost half $(9.4 \mathrm{~h} /$ week vs. $5.3 \mathrm{~h} /$ week), a statistically significant difference $(t=16.261, p<0.001)$. In addition, all sports and training camps were canceled during the study period, with $60.8 \%$ of study participants reporting difficulties due to insufficient contact with assistants/caregivers or due to lack of access to assistive training devices. Over $74 \%$ of athletes were not satisfied with their abilities to train during the pandemic. 
Table 1 Socio-demographic and injury characteristic of 166 athletes with disabilities

\begin{tabular}{|c|c|c|}
\hline \multirow[t]{2}{*}{$\begin{array}{l}\text { Socio-demographic and injury } \\
\text { characteristic }\end{array}$} & \multicolumn{2}{|c|}{$\begin{array}{l}\text { Athletes with } \\
\text { disabilities }(n=166)\end{array}$} \\
\hline & $\mathrm{n}$ & (\%) \\
\hline \multicolumn{3}{|l|}{ Gender } \\
\hline Male & 106 & (63.9) \\
\hline Female & 60 & (36.1) \\
\hline \multicolumn{3}{|l|}{ Marital status } \\
\hline Single & 105 & (63.3) \\
\hline In relationship & 61 & $(24.1)$ \\
\hline \multicolumn{3}{|l|}{ Place of living } \\
\hline Urban area & 126 & $(76.5)$ \\
\hline Rural area & 39 & $(23.5)$ \\
\hline \multicolumn{3}{|l|}{ Education } \\
\hline Higher & 160 & (96.4) \\
\hline Elementary/vocational & 6 & (3.6) \\
\hline \multicolumn{3}{|l|}{ Professional status } \\
\hline Employed & 146 & $(88.0)$ \\
\hline Unemployed & 20 & (12.0) \\
\hline \multicolumn{3}{|l|}{ Sport discipline } \\
\hline Archery & 7 & $(4.2)$ \\
\hline Athletics & 39 & $(23.5)$ \\
\hline Boccia & 4 & $(2.4)$ \\
\hline Canoe & 2 & $(1.2)$ \\
\hline Cycling & 7 & $(4.2)$ \\
\hline Goalball & 9 & $(5.4)$ \\
\hline Powerlifting & 15 & $(9.0)$ \\
\hline Rowing & 6 & (3.6) \\
\hline Shooting & 5 & (3.0) \\
\hline Swimming & 25 & $(15.1)$ \\
\hline Sitting volleyball & 11 & $(6.6)$ \\
\hline Table tennis & 10 & $(6.0)$ \\
\hline Wheelchair fencing & 5 & (3.0) \\
\hline Wheelchair rugby & 8 & $(4.8)$ \\
\hline Wheelchair basketball & 13 & $(7.8)$ \\
\hline \multicolumn{3}{|l|}{ Type of disability } \\
\hline Paraplegia & 21 & (12.6) \\
\hline Tetraplegia & 22 & (13.3) \\
\hline Muscular dystrophy & 3 & $(1.8)$ \\
\hline Heine-Medina (poliomyelitis) & 2 & $(1.2)$ \\
\hline Spina bifida & 10 & $(6.0)$ \\
\hline Cerebral palsy & 14 & $(8.4)$ \\
\hline Limb amputations & 37 & $(22.2)$ \\
\hline Multiple sclerosis & 2 & $(1.2)$ \\
\hline Other & 55 & $(33.1)$ \\
\hline
\end{tabular}

The sport of people with disabilities undergoes rapid professionalization [19]. For a long time, an erroneous tendency existed to conduct research on athletes with disabilities with the same mindset as the one applied to studies on non-disabled athletes. Today, it is known that sport plays a special role for persons with disabilities, increasing their socialization, self-esteem, quality of life and independence $[17,20]$. Therefore, it is even more important to continue monitoring the pandemic's influence on athletes with disabilities preparing for elite sport events.

The present study was conducted in cooperation with the European Paralympic Committee and the Polish Paralympic Committee. Its practical goal was to promote effective cooperation in order to produce and exchange information about feasible solutions which could be beneficial in similar future scenarios. The survey was conducted in the initial phase of the epidemic in Poland, when the number of reported infections did not exceed five hundred cases a day. As of January 6, 2021, the official data given by the Polish government indicate that over 1,300,000 people in Poland have become infected with and more than 30,000 died due to COVID-19, with the highest daily increase in the number of infections amounting to about 30,000 [1].

\section{Conclusions}

The strength of this study resides in very high response rate and capturing the most restricted period of pandemic in Poland. Almost all Polish Paralympic Athletes preparing to Paralympic Games Tokyo 2021 took part in this study during period were all sports facilities were closed, and even ability to train outdoor was very limited. The present study showed that the Polish Paralympic athletes with disabilities have been strongly affected by the pandemic and measures undertaken to slow its spread, especially by the lockdown. Since they were often prevented from regular training, their preparation process for the Paralympic Games in Tokyo was disturbed during the observed 1 month of pandemic lockdown. Further longitudinal studies with cooperation of the National Paralympic Committees and other sports institutions are definitely warranted to counteract the effects of the pandemic on athletes with disabilities.

\section{Limitations}

There are some limitations to the present study. First, the study used self-designed questionnaire what limited possibility to compare study results with previous research. Secondly, the study did not investigate participants' psychological factors such as anxiety, depression, or coping strategies that may influence abilities to undertake training under stressful periods.

\section{Supplementary Information}

The online version contains supplementary material available at https://doi. org/10.1186/s13104-021-05646-0. 
Additional file 1. Impact of COVID-19 pandemic on Paralympic athletes

\section{Acknowledgements}

Not applicable.

\section{Authors' contributions}

PU and TT contributed to the conceptualization, design of the study and realization of the study, interpretation of results, drafting and critically revising the manuscript; PU and LS collected the data; additionally LS contributed to drafting and critically revising the manuscript. All authors read and approved the final manuscript.

\section{Funding}

Not applicable.

\section{Availability of data and materials}

The datasets generated and/or analysed during the current study are available from the corresponding author on reasonable request.

\section{Declarations}

\section{Ethics approval and consent to participate}

The study was conducted in conformity with the Declaration of Helsinki [21]. As online surveys or questionnaires do not require the completion of a separate participant information sheet or consent form, completion of the survey was deemed to constitute informed consent. The Bioethics Committee at the Medical University in Poznan, Poland, provided a confirmation that according to national regulations there is no need for an ethical review of this study as this does not involve any experiment.

\section{Consent for publication}

Not applicable.

\section{Competing interests}

The authors declare that they have no competing interests.

\section{Author details}

${ }^{1}$ Department of Adapted Physical Activity, Poznan University of Physical Education, Poznań, Poland. ${ }^{2}$ Polish Paralympic Committee and Polish Sports Association for the Disabled 'Start', Warsaw, Poland.

Received: 28 January 2021 Accepted: 9 June 2021

Published online: 14 June 2021

\section{References}

1. World Health Organisation. Coronavirus disease (COVID-19) pandemic [Internet]. 2020. https://www.euro.who.int/en/health-topics/healthemergencies/coronavirus-covid-19/novel-coronavirus-2019-ncov. Accessed 15 Oct 2020.

2. Academy USS. COVID-19: social isolation and optimism in sport [Internet]. The Sport Journal. 2020. https://thesportjournal.org/article/covid-19social-isolation-and-optimism-in-sport/. Accessed 15 Oct 2020.

3. The Impact of Global Economic Downturn on Sport Management [Internet]. Campaign Page Builder. 2020. https://think.taylorandfrancis.com/ special_issues/sport-management-covid-19/. Accessed 15 Oct 2020.

4. Jagim AR, Luedke J, Fitzpatrick A, Winkelman G, Erickson JL, Askow AT, et al. The impact of COVID-19-related shutdown measures on the training habits and perceptions of Athletes in the United States: a brief research report. Front Sports Act Living. 2020. https://doi.org/10.3389/fspor.2020. 623068/full.
5. Wong AYY, Ling SKK, Louie LHT, Law GYK, So RCH, Lee DCW, et al. Impact of the COVID-19 pandemic on sports and exercise. Asia Pac J Sports Med Arthrosc Rehabil Technol. 2020;22:39-44.

6. Jukic I, Calleja-González J, Cos F, Cuzzolin F, Olmo J, Terrados N, et al. Strategies and solutions for team sports athletes in isolation due to COVID-19. Sports. 2020;8(4):56.

7. Mehrsafar AH, Gazerani P, Moghadam Zadeh A, Jaenes Sánchez JC Addressing potential impact of COVID-19 pandemic on physical and mental health of elite athletes. Brain Behav Immun. 2020;87:147-8.

8. Andreato LV, Coimbra DR, Andrade A. Challenges to athletes during the home confinement caused by the COVID-19 pandemic. Strength Cond J [Internet]. 2020. https://www.ncbi.nlm.nih.gov/pmc/articles/PMC72 19846/. Accessed 15 Oct 2020.

9. Ruihley BJ, Li B. Sport and the coronavirus crisis special issue: an introduction. Int J Sport Commun. 2020;13(3):289-93.

10. Lesser IA, Nienhuis CP. The impact of COVID-19 on physical activity behavior and well-being of Canadians. Int J Environ Res Public Health. 2020;17(11):3899.

11. WHO | Global recommendations on physical activity for health [Internet]. WHO. World Health Organization. https://www.who.int/dietphysicalact ivity/publications/9789241599979/en/. Accessed 1 June 2020.

12. Clemente-Suárez VJ, Fuentes-García JP, de la Vega Marcos R, Martínez Patiño MJ. Modulators of the personal and professional threat perception of Olympic Athletes in the actual COVID-19 crisis. Front Psychol [Internet]. 2020;11. https://www.frontiersin.org/articles/https://doi.org/ 10.3389/fpsyg.2020.01985/full?\&utm_source=Email_to_authors_\&utm_ medium=Email\&utm_content=T1_11.5e1_author\&utm_campaign = Email_publication\&field $=\&$ journalName $=$ Frontiers_in_Psychology\&id $=$ 564947. Accessed 5 Jan 2020.

13. Wilber N, Mitra M, Walker DK, Allen D, Meyers AR, Tupper P. Disability as a public health issue: findings and reflections from the Massachusetts survey of secondary conditions. Milbank Q. 2002;80(2):393-421.

14. European Disability Forum. Cermi-people with disabilities and their families and the coronavirus health crisis: compendium of recommendations for the short-term management of the pandemic. European Disability Forum; 2020.

15. Dantas MJB, Dantas TLFS, da Júnior PDJ, de Neto OL, Gorla JI. COVID19: Considerations for the disabled athlete. Rev Bras Fisiol Exerc. 2020;19(2):30-4.

16. Lebrasseur A, Fortin-Bédard N, Lettre J, Bussières E-L, Best K, Boucher N et al. Impact of COVID-19 on people with physical disabilities: a rapid review. Disabil Health J. 2021;14(1):101014.

17. Urbański P, Kim Y, Conners R, Nadolska A, Tasiemski T. Life satisfaction in persons with spinal cord injury across the seasons. Spinal Cord. 2020;1:1-8.

18. Shaw KA, Bertrand L, Deprez D, Ko J, Zello GA, Chilibeck PD. The impact of the COVID-19 pandemic on diet, fitness, and sedentary behaviour of elite para-athletes. Disabil Health J. 2021. https://doi.org/10.1016/j.dhjo.2021. 101091.

19. Brittain: The evolution of the Paralympic Games - Google Scholar [Internet]. https://scholar.google.com/scholar_lookup?title=The\%20evo lution\%20of\%20the\%20Paralympic\%20Games\&author=1.\%20Brittain\& pages=19-34\&publication_year=2008. Accessed 30 Apr 2021.

20. Rivers CS, Fallah N, Noonan VK, Whitehurst DG, Schwartz CE, Finkelstein $J A$, et al. Health conditions: effect on function, health-related quality of life, and life satisfaction after traumatic spinal cord injury. A prospective observational registry cohort study. Arch Phys Med Rehabil. 2018;99(3):443-51.

21. WMA Declaration of Helsinki. World Medical Association; 1964.

\section{Publisher's Note}

Springer Nature remains neutral with regard to jurisdictional claims in published maps and institutional affiliations. 